\title{
An Empirical Analysis of the Influence of Financial Literacy on Family Cultural Consumption - Based on the Data from CFPS
}

\author{
Yanhong Gong, Ziwen Song* \\ Tibet University, Lhasa 850000, China \\ *Corresponding author: Ziwen Song, 1021393312@qq.com
}

\begin{abstract}
Based on the data from Chinese Family Panel Studies (CFPS), this study uses the Tobit model to empirically analyze the influence of financial literacy on family cultural consumption. This study found that the average financial literacy level of Chinese residents is still relatively low. The improvement of their financial literacy would help enhance the household cultural consumption expenditure. From this study, it is recommended that there should be an improvement in the cultural consumption of Chinese families and their quality of life by targeting financial education, raising the income level of residents, and stimulating the residents' cultural consumption willingness.
\end{abstract}

Keywords: Financial literacy; Cultural consumption; Tobit model; Regional differences

Publication date: December 2021; Online publication: December 31, 2021

\section{Introduction}

As economic development transitions into the new normal, consumption has become the impetus for the economic growth in China. As a new consumption format, cultural consumption plays an important role in meeting people's needs for a better life and promoting economic growth ${ }^{[4]}$. In recent years, although the absolute expenditure of Chinese residents in terms of cultural consumption has increased substantially, its growth rate has been declining. The proportion of cultural consumption in per capita GDP has shown a trend of first, rising and then, falling. In this context, many scholars have carried out research on the influencing factors of cultural consumption, of which most of them have been attributed to the macro and micro levels. As an important human capital, financial literacy plays an increasingly important role in the consumption decision-making process ${ }^{[8]}$. The differences in financial literacy among urban and rural households, as well as families in eastern, central, and western regions, are obvious. Therefore, studying the influence of financial literacy on family cultural consumption in urban and rural households as well as the heterogeneity in eastern, central, and western regions are of profound significance to the growth of the economy in China.

\section{Literature review}

The economic research on cultural consumption can be traced back to the nineteenth century. Veblen proposed that cultural consumption is a "conspicuous consumption" and recognized the positive correlation between cultural consumption and income ${ }^{[1]}$. Since then, scholars have carried out much research on the role of cultural consumption in the economy and society. Research on the relationship between residents' income level and cultural consumption has shown that there is a positive correlation between the two ${ }^{[2,3]}$. Whether it is consumption or cultural consumption, income is the most decisive factor. In addition, many 
scholars have conducted research on the influencing factors of cultural consumption from different factors and perspectives. The consumers' educational level, residents' educational expenditures, and policy tendencies all have an impact on cultural consumption ${ }^{[4,5]}$. A number of scholars have also analyzed the impact of urban residents' household registration differences, government public cultural expenditures, and other factors on cultural consumption ${ }^{[6,7]}$.

With the development of digital economy and the advancement of science and technology, financial literacy is an important human capital (Delavande, 2008). Its important role in the economy and society has increasingly become the focus of attention. However, research has shown that on the whole, the financial literacy level of residents in all the countries around the world is relatively low, and they lack basic financial knowledge ${ }^{[8,9]}$. Regarding the important role of financial literacy, it is mainly manifested in its impact on the family and social levels ${ }^{[10-13]}$.

By combing the relevant literatures at home and abroad, it can be appreciated that there is not much research on the influence of financial literacy on family cultural consumption. Therefore, this study draws on existing research in the field of financial literacy and cultural consumption to explore the mechanism of action between financial literacy and family cultural consumption.

\section{Data, model, and variable description}

\subsection{Data source and description}

The data used in this study are based on the Chinese Family Panel Studies (CFPS) conducted by the Institute of Social Science Survey of Peking University. Since CFPS (2014) has a financial knowledge module, it is convenient to measure the variables in this study. This module has been removed from the database of CFPS over several years, so this study has chosen the database of CFPS (2014).

\subsection{Model setting}

In the sample households, since the cultural and entertainment expenditures of many households are zero, simply using the least squares method to estimate the results of the multivariate OLS model will produce large deviations. Therefore, this study has adopted the Tobit model to estimate the impact of financial literacy on cultural consumption. The basic model is as follows:

$$
\left\{\begin{array}{c}
C C_{i}=\alpha_{0}+\alpha_{i} F K_{i}+\beta X_{i}+\mu_{i} \\
C C^{*}=\max (\square \square \square \square)
\end{array}\right.
$$

Equation (1) is the intercepted Tobit model. The error term is independent and obeys a normal distribution; among them, represents the cultural consumption of family $i$, which represents the part of family cultural consumption greater than $0 . F K$ refers to financial literacy, and $X$ refers to the control variables.

\subsection{Variable explanation and description}

\subsubsection{Explained variable}

The explained variable is cultural consumption (CC). This study referred to the practice of Zeng Yanping and other scholars ${ }^{[6]}$, selected data on household cultural and entertainment expenditure, household net income, and total household expenditure from the CFPS database, and used household cultural and entertainment expenditure as a percentage of household net income. The ratio $\mathrm{CC} 1$ and the ratio of cultural and entertainment expenditure to the total household expenditure, $\mathrm{CC} 2$, were used as proxy variables of cultural consumption, and the benchmark regression was performed. 


\subsubsection{Core explanatory variables}

This study divided financial literacy into knowledge-based financial literacy and skill-based financial literacy, denoted as FK1 and FK2, respectively. Knowledge-based financial literacy includes four aspects: investment product description, fund description, wealth management product description, and stock market function description. A score of 1 was assigned for each correct answer, and no scores were given for wrong answers or if the respondents did not know the answer. Skill-based financial literacy includes 9 aspects: paying attention to financial status, formulating long-term financial planning, subjective feelings, subjective tendencies, financial income and expenditure management, consumption patterns, choosing financial product models, bookkeeping habits, and difficulty in fundraising, which are completely inconsistent to complete compliance. Scores from 1 to 5 were assigned, respectively.

Drawing from the practice of various scholars, such as Yin Zhichao ${ }^{[14]}$, and using principal component analysis to construct financial literacy indicators, this study used principal component analysis to extract common factors: two principal components from knowledge-based financial literacy, and four principal components from skill-based financial literacy. The cumulative variance of the original variables that can be explained is more than $60 \%$. When calculating factor scores, this study multiplied each factor by the corresponding variance contribution rate to obtain the comprehensive factor scores of FK1 and FK2.

\subsubsection{Control variable}

In addition to the above variables, this study also included a set of control variables that may affect family cultural consumption, specifically family characteristic variables (per capita net income and per capita financial assets) and personal characteristic variables (gender, age, marital status, education, and household registration type). In terms of family characteristics, in order to avoid heteroscedasticity, the logarithm of per capita net income and per capita financial assets were recorded as lnincome and lnasset, respectively. In terms of personal characteristics, gender was recorded as sex; according to the gender of the respondents, male was assigned a value of 1 , female was assigned a value of 0 ; age was recorded as age, and the age of the respondents was calculated based on the year 2014; the marital status was recorded as marriage; those unmarried were assigned a value of 0 , while those married or widowed were assigned a value of 1 ; education was recorded as education; those with high school education were assigned a value of 1, while those below high school education were assigned a value of 0 ; the type of household registration was recorded as urban; a value of 1 was assigned for non-agricultural household registration and 0 for agricultural household registration.

\section{Empirical test}

First, financial literacy was used to make a benchmark regression on the residents' cultural consumption variables. As can be seen from columns 1-4 in Table 1, after adding the control variables, the marginal coefficient of both knowledge-based financial literacy and skill-based financial literacy is significant at the $1 \%$ level, indicating that financial literacy can promote the cultural consumption of Chinese households. Looking at columns 5-8 in the table, it can be seen that the marginal coefficients of knowledge-based financial literacy and skill-based financial literacy are significant at the level of $1 \%$ and $10 \%$, respectively, after adding the control variables, again indicating that the improvement of residents' financial literacy can drive the cultural consumption in China to a higher level. The possible reasons are as follows: first, in recent years, China's financial market has been booming, and people have begun to purchase financial products for financial planning rather than just depositing in banks to earn interest; with the gradual improvement of people's financial literacy, it has effectively prevented financial fraud and promoted the borrowing behavior of Chinese residents, which in turn result in asset appreciate and the improvement of residents' cultural 
consumption ability; second, with the improvement of the country's economic level and people's living standards, people has begun to pursue spiritual consumption instead of simple material consumption, thus increasing the willingness of Chinese residents for cultural consumption. Taking into consideration of the above two points, the improvement of financial literacy has enhanced the cultural consumption level of Chinese residents to a large extent.

Among the family-level control variables, the marginal coefficient of the logarithm lnincome of the family's per capita net income is different in the regression of CC1 and CC2. In CC1 regression, the coefficient is negative. The reason may be that the explained variable is the proportion of entertainment expenditure in the household net income, so the influence of the increase in household net income per capita on the explained variable is biased; the marginal coefficient of CC2 is positive, indicating that the increase in per capita net income can promote cultural consumption. The coefficients of household financial assets lnasset are all significantly positive at the level of $1 \%$, indicating that households having more financial assets can promote the level of cultural consumption as more financial assets may bring higher income to residents, thus increasing the cultural consumption expenditure.

Among the control variables at the individual level, the marginal coefficients of gender are not significant in $\mathrm{CC} 1$ and $\mathrm{CC} 2$ regressions. It can be seen that gender does not have a particularly significant impact on the residents' cultural consumption. The coefficient of age in the regression is significantly negative at the $1 \%$ level, indicating that younger residents have a higher cultural consumption demand, which helps to increase the family's cultural consumption, while older residents have backward consumption concepts and cultural consumption. The low demand limits the growth of cultural consumption. This verifies the research conducted by Zeng Yanping and Liu Xia ${ }^{[6]}$. The coefficients of marriage are all significantly positive but with low significant levels, indicating that the influence of marital status on cultural consumption is not very obvious. The mechanism of this variable's influence on cultural consumption can be explained by most residents after getting married. A relatively stable family and the gradual improvement in living standards have made them pay more attention to cultural consumption on the spiritual level. The coefficient of the household registration type is not significant, indicating that urban household registration can promote cultural consumption to a certain extent, but the influence is minimal. This is because there is a huge gap between urban and rural areas in the country in terms of their income levels, education level, and consumption concept. The phenomenon of large-scale rural population migration has already improved. 
Table 1. Benchmark regression results

\begin{tabular}{|c|c|c|c|c|c|c|c|c|}
\hline \multirow[t]{2}{*}{ Variable } & \multicolumn{4}{|c|}{$\begin{array}{l}\text { The ratio of entertainment expenditure to household } \\
\text { net income, } \mathrm{CC} 1\end{array}$} & \multicolumn{4}{|c|}{$\begin{array}{l}\text { The proportion of entertainment expenditure to total } \\
\text { household expenditure, } \mathrm{CC} 2\end{array}$} \\
\hline & (1) & (2) & (3) & (4) & (5) & (6) & (7) & (8) \\
\hline FK1 & $\begin{array}{c}0.9010^{* * * *} \\
(0.1401)\end{array}$ & $\begin{array}{c}0.0486 * * * \\
(0.0137)\end{array}$ & & & $\begin{array}{c}0.0083^{* * *} \\
(0.0007)\end{array}$ & $\begin{array}{c}0.0047 * * * \\
(0.0009)\end{array}$ & & \\
\hline FK2 & & & $\begin{array}{c}1.2245^{* * *} \\
(0.1637)\end{array}$ & $\begin{array}{c}0.0610^{* * *} \\
(0.0168)\end{array}$ & & & $\begin{array}{c}0.0088 * * * \\
(0.0008)\end{array}$ & $\begin{array}{c}0.0032 * * * \\
(0.0011)\end{array}$ \\
\hline lnincome & & $\begin{array}{c}-0.0423 * * * \\
(0.0083)\end{array}$ & & $\begin{array}{c}-0.0427 * * * \\
(0.0083)\end{array}$ & & $\begin{array}{c}0.0031^{* * *} \\
(0.0006)\end{array}$ & & $\begin{array}{c}0.0032^{* * *} \\
(0.0006)\end{array}$ \\
\hline lnasset & & $\begin{array}{c}0.0360^{* * * *} \\
(0.0048)\end{array}$ & & $\begin{array}{c}0.0346 * * * \\
(0.0049)\end{array}$ & & $\begin{array}{c}0.0015^{* * * *} \\
(0.0003)\end{array}$ & & $\begin{array}{c}0.0015^{* * *} \\
(0.0003)\end{array}$ \\
\hline sex & & $\begin{array}{c}0.0026 \\
(0.0137)\end{array}$ & & $\begin{array}{c}0.0037 \\
(0.0137)\end{array}$ & & $\begin{array}{l}-0.0002 \\
(0.0009)\end{array}$ & & $\begin{array}{l}-0.0002 \\
(0.0009)\end{array}$ \\
\hline age & & $\begin{array}{c}-0.0017 * * * \\
(0.0005)\end{array}$ & & $\begin{array}{c}-0.0017 * * * \\
(0.0005)\end{array}$ & & $\begin{array}{c}-0.0001 * * * \\
(0.00003)\end{array}$ & & $\begin{array}{r}-0.0001 * * * \\
(0.00003)\end{array}$ \\
\hline marriage & & $\begin{array}{l}0.0291 * \\
(0.0233)\end{array}$ & & $\begin{array}{l}0.0267^{*} \\
(0.0233)\end{array}$ & & $\begin{array}{l}0.0014^{*} \\
(0.0015)\end{array}$ & & $\begin{array}{l}0.0015^{*} \\
(0.0015)\end{array}$ \\
\hline educatio & & $0.0287 * *$ & & $0.0297 * *$ & & $0.0023 * *$ & & $0.0025^{* * *}$ \\
\hline $\mathrm{n}$ & & $(0.0146)$ & & $(0.0145)$ & & (0.0009) & & (0.0009) \\
\hline urban & & $\begin{array}{l}-0.0008 \\
(0.0176) \\
\end{array}$ & & $\begin{array}{c}0.0033 \\
(0.0175) \\
\end{array}$ & & $\begin{array}{c}0.0004 \\
(0.0011) \\
\end{array}$ & & $\begin{array}{c}0.0008 \\
(0.0011) \\
\end{array}$ \\
\hline
\end{tabular}

Note: The numbers in parentheses are standard errors; *,**,*** indicate that the results are significant at the level of $10 \%, 5 \%$, and $1 \%$, respectively.

\section{Conclusion and policy recommendations}

Based on the family economic data from the Chinese Family Panel Studies (CFPS) in 2014, this study used the Tobit model to empirically analyze the impact of financial literacy on family cultural consumption. This study found that the improvement of residents' financial literacy can drive the country's cultural consumption level. There are several policy recommendations pertaining to this field.

First, it is necessary to increase investment in financial education and give full play to the role of financial literacy in promoting cultural consumption. Providing a stable source of funds for financial education by increasing financial investment in financial literacy education, incorporating financial education into the national development strategy layout, and carrying out financial education through multiple channels would be beneficial as well.

Second, effective government control measures should be formulated to increase the income level of residents. The government should increase the disposable income of residents by raising the minimum wage standard, establishing a wage increase mechanism, increasing transferable income, and improving the social security system to increase the residents' disposable income, thereby increasing their cultural consumption ability.

Third, it is also important to optimize the cultural consumption environment and stimulate the willingness of the residents for cultural consumption. Creating a good social and cultural environment, making good use of the development of internet technology, providing residents with a variety of highquality cultural products in various forms, increasing residents' cultural consumption willingness from the 
perspective of cultural service supply, and stimulating cultural consumption expenditure would be beneficial.

\section{Funding}

This research was supported by the 2017 National Natural Science Foundation of China (Project Number: 71763025) and Mt. Everest Curriculum Set-up Program of Tibet University (Project Number: zf21003004).

\section{Disclosure statement}

The authors declare that there is no conflict of interest.

\section{References}

[1] Veblen T, 1899, Mr. Cummings's Strictures on "The Theory of the Leisure Class". Journal of Political Economy, 8(1): 106-117.

[2] Cameron S, 1990, The Demand for Cinema in the United Kingdom. Journal of Cultural Economics, 14(1): 35-47.

[3] Liu T, Song B, 2020, Research on the Leisure Consumption of Migrant Workers' Family from the Perspective of New Urbanization - Based on the Analysis of Income Effect and Cultural Effect. Rural Economy, 2020(12): 77-86.

[4] Yang J, Huang X, Li X, 2008, Educational Inequality and Income Distribution Gap: An Empirical Analysis of China. Management World, 2008(01): 38-47, 187.

[5] Lu L, 2009, The Regional Difference and Dynamic Effect Analysis of the Influencing Factors of Cultural Consumption of Rural Residents. Statistics and Decision, 2009(09): 81-83.

[6] Zeng Y, Liu X, 2020, Research on the Impact of Government Public Cultural Expenditure on Family Cultural Consumption - Based on the Analysis of Chinese Family Tracking Survey. Consumer Economy, 36(02): 29-39.

[7] Zhong F, Li S, 2021, The Impact of Urban Residents' Household Registration Differences on Cultural Consumption - Based on the Analysis of China's Comprehensive Social Survey Data. Consumer Economy, 2021: 1-12.

[8] Lusardi A, Mitchell OS, 2007, Baby Boomers Retirement Security: The Role of Planning, Financial Literacy and Housing Wealth. Journal of Monetary Economics, 54: 205-224.

[9] Yin Z, Song Q, Wu Y, Peng C, 2015, Financial Knowledge, Entrepreneurial Decision-Making and Entrepreneurial Motivation. Management World, 2015(01): 87-98.

[10] Qin F, Wang W, He J, 2016, The Influence of Financial Knowledge on Participation in Commercial Insurance - An Empirical Analysis of Data from the China Household Finance Survey (CHFS). Financial Research, 2016(10): 143-158.

[11] Song Q, Wu Y, Yin Z, 2017, Research on Household Credit Behavior from the Perspective of Financial Knowledge. Financial Research, 2017(06): 95-110.

[12] Hu Z, Zang R, 2017, Research on the Impact of Financial Literacy on Family Financial Planning Micro-evidence from Chinese Urban Households. Journal of Central University of Finance and Economics, 2017(02): 72-83.

[13] Shan D, 2019, Financial Literacy and Urban Poverty. China Industrial Economics, 2019(04): 136-154. 
[14] Yin Z, Song Q, Wu Y, 2014, Financial Knowledge, Investment Experience and Household Asset Selection. Economic Research, 49(04): 62-75.

[15] Hong Y, 2017, Major Innovations in China's Economic Development Theory After Entering a New Stage. China Industrial Economics, 2017(05): 5-15.

[16] Meng H, Yan X, 2019, Financial Literacy, Household Leverage and Household Consumption. Financial Development Research, 2019(12): 30-39. 